ORIGINAL ARTICLE

\title{
Time trends in the incidence of myocardial infarction among professional drivers in Stockholm 1977-96
}

\author{
C Bigert, K Klerdal, N Hammar, J Hallqvist, P Gustavsson
}

Occup Environ Med 2004;61:987-991. doi: 10.1136/oem.2004.012781

See end of article for authors' affiliations

......................

Correspondence to: Dr C Bigert, Department of Occupational and Environmental Health, Norrbacka, Karolinska Hospital, SE-171 76 Stockholm, Sweden: bigert@telia.com

Accepted 5 July 2004

\begin{abstract}
Aims: To investigate time trends in the incidence of first myocardial infarction (MI) among bus, taxi, and lorry drivers in Stockholm.

Methods: In this population based case-control study, all first events of acute Ml among men aged 40-69 in Stockholm County 1977-96 were identified using registers of hospital discharges and deaths. Controls were selected randomly from the general population. National censuses were used for information on occupational titles. A total of 20364 cases and 136342 controls were included in the study. Among these, 1183 cases and 6072 controls had worked as drivers.

Results: During 1977-84 the Ml incidence was higher in all three driver groups than among other manual workers. There was a decline in $\mathrm{Ml}$ incidence among drivers as well as in the general population during the study period. The decline was greater among drivers than among other manual workers. During 1985-96 the relative risk remained increased compared to other manual workers among taxi and lorry drivers, but not among bus drivers.

Conclusions: Despite a reduced Ml incidence for professional drivers in recent years, preventive measures to reduce the risk of $\mathrm{Ml}$ in these occupational groups, and in particular among taxi and lorry drivers, continue to be of importance.
\end{abstract}

A n increased risk of myocardial infarction (MI) among professional drivers was first reported about 50 years ago $^{1}$ and has been reported repeatedly since then, especially among bus drivers. ${ }^{2}{ }^{3}$ The underlying causes for this increased risk are not fully understood and have been attributed to chemical and psychosocial factors in the work environment as well as to an overrepresentation of established coronary risk factors among drivers. ${ }^{245}$ A previous investigation of drivers in Stockholm showed an excess of MI among bus and taxi, as well as among lorry drivers. ${ }^{6}$ Adjusting for smoking habits, alcohol habits, physical inactivity at leisure time, overweight, diabetes, and hypertension, as well as socioeconomic status showed that nearly all of the excess risk among the lorry drivers could be explained by these factors, while this was not the case for bus and taxi drivers.

In Sweden and other western countries there has been a decline in the incidence and mortality from ischaemic heart disease during the past 20 years. ${ }^{7-9}$ The incidence of acute MI in the general population in Stockholm increased during the $1970 s^{10}$ followed by a decline starting in the early $1980 \mathrm{~s},{ }^{11}$ continuing during the period 1984-96. ${ }^{12}$ The time trend in incidence among manual workers has shown a similar pattern, although at a higher level and with a later peak. ${ }^{13}$ It is not known to what extent the MI incidence among drivers has changed in recent years.

The objective of this study was to investigate time trends in the incidence of MI among various categories of professional drivers in Stockholm, Sweden, during the 20 year period 1977-96. We also wanted to examine to what extent an increased incidence was present among professional drivers compared to other manual workers during this period.

Due to the small number of MI cases among female drivers during the study period (seven cases among bus drivers, five among taxi drivers, and three among lorry drivers), the focus of this study is on male drivers.

\section{METHODS \\ Study population and identification of cases and controls}

The study population consisted of men aged 40-69 years in Stockholm County followed for first time MI during the period 1977-96. We identified incident cases of acute MI in the study population using registers of hospital discharges and deaths in accordance with a previously developed and validated method. ${ }^{12}{ }^{1415}$ Cases with a previous MI were excluded using registers of Stockholm County going back to 1972. For the period 1977-84, data used in this study were compiled in the late 1980s. ${ }^{16}{ }^{17}$ For the years 1985-96 data were compiled more recently and in a similar fashion, but with a more extensive sample of controls (see below). In total, we identified 10361 incident first MI cases 1977-84 and 12611 cases 1985-96. We selected controls randomly from the general population using registers of the total population of Stockholm County on 31 December each year (1976-84 for the period 1977-84, and 1984-96 for the period 1985-96). In the sampling of controls we stratified by gender, age (five year age groups), and calendar year. For the period 1977-84 we selected two controls for each case (first as well as recurrent). For the period 1985-96 we selected a total of 1500 controls per stratum. Controls selected for the period 1985-96 with a previous MI were excluded using information from registers of Stockholm County going back to 1972 and national registers going back to 1987. Information on previous MI was not available for controls selected for the period 1977-84.

Information on occupation and socioeconomic group We obtained information about occupation, branch of industry, and socioeconomic group for cases and controls using national censuses. For the period 1977-84 we used the

Abbreviations: $\mathrm{Cl}$, confidence interval; $\mathrm{RR}$, relative risk 
Main messages

- During the 20 year period 1977-96 there was a greater decline in $\mathrm{Ml}$ incidence among professional drivers than in the general population and among other manual workers.

- In spite of this favourable trend the relative risk of MI remained increased among taxi and lorry drivers during the entire period compared to other manual workers.

- The incidence of $\mathrm{Ml}$ among bus drivers approached that among other manual workers and was not increased during the latter part of the study period.

censuses in 1970 and 1975 (for technical reasons the census in 1980 was not available for the period 1981-84), and for the period 1985-96 the censuses in 1975, 1980, 1985, and 1990. Statistics Sweden transformed the occupational codes for censuses in 1985 and 1990 to the Nordic occupational code of $1980 .{ }^{18}$ Branch of industry was coded according to the Swedish standard of industrial classification. ${ }^{19}$ We distinguished between bus drivers, taxi drivers, and lorry drivers by means of combining the occupational code for "motor vehicle driver" (code 633) with the appropriate branch of industry code (see Appendix). A subject was classified as a professional driver if he had reported working as such in any of the two censuses preceding the year of inclusion. If the type of vehicle they were driving changed over the preceding two censuses they were included in both driver categories. During the period 1977-96, 241 cases of MI and 1339 controls had worked as bus drivers, 315 cases and 1436 controls had worked as taxi drivers, and 661 cases and 3481 controls had worked as lorry drivers.

In the Swedish system for classifying socioeconomic group, ${ }^{20}$ subjects are subdivided into manual workers, nonmanual employees, and self-employed. We classified socioeconomic group for cases and controls primarily from the preceding census. If the subject was not employed at that census we used information from the next previous census back in time. Subjects without employment in both of the two latest censuses were excluded. In the 1970 and 1975 censuses there was no classification of socioeconomic group performed by Statistics Sweden. We performed a classification of socioeconomic group for these years according to the same principles as in the census of $1980 .{ }^{21}$ Table 1 presents the number of cases and controls included in the study (after exclusion of persons with previous MI or no information on occupation).

\section{Statistical methods}

Age standardised (five year age groups) incidence rates were calculated by two year calendar periods for different categories of professional drivers, for manual workers other than professional drivers (below denoted other manual workers), and for all gainfully employed other than professional drivers (below denoted other gainfully employed), respectively. The population total was derived by multiplying the prevalence of the different categories among the controls with the number of persons in Stockholm County in each stratum. The person-time at risk used in the incidence estimates was calculated as the average of the population total at 31 December in the previous and the current year. The age distribution for men aged 40-69 in Stockholm County in 1990 was used in the age standardisation. The variance of the incidence was calculated using the Gauss approximation formula. We estimated the average annual change in

\section{Policy implications}

- Despite a reduced Ml incidence for professional drivers in recent years, preventive measures to reduce the risk of $\mathrm{Ml}$, in particular among taxi and lorry drivers, continue to be of importance.

incidence of first MI during the study period in relative terms by Poisson regression, adjusting for secular changes in the age distribution, and also in absolute terms by calculating the average yearly change in incidence per 10000 personyears by linear regression. The association between work as a professional driver and first acute MI was evaluated by computing odds ratios from stratified analysis in accordance with the Mantel-Haenszel method, adjusting for age group (five year) and calendar year (four year). In these analyses, we used other manual workers or other gainfully employed subjects, respectively, as reference group. In addition we performed analyses restricted to persons holding the same type of job (occupation and branch of industry) in two censuses preceding inclusion in the study as case or control, going back at most 14 years. In view of the study design the odds ratios may be interpreted as relative risks or estimates of incidence density ratios and will be denoted relative risks (RR) throughout the text. Random variation was accounted for by computing 95\% confidence intervals. We used the SAS statistical software throughout the analyses.

\section{RESULTS}

The incidence of MI was increased in all three drivers groups compared to other manual workers during 1977-84 (table 2): bus drivers, $\mathrm{RR}=1.30$ (95\% CI 1.03 to 1.64 ); taxi drivers, $\mathrm{RR}=1.38(95 \% \mathrm{CI} 1.12$ to 1.71$)$; lorry drivers, $\mathrm{RR}=1.14(95 \%$ CI 1.00 to 1.30 ). Among taxi and lorry drivers the relative risk remained increased during 1985-96, but for bus drivers no increased incidence was seen in 1985-96 $(\mathrm{RR}=1.03,95 \% \mathrm{CI}$ 0.86 to 1.25 ). Taxi drivers had the highest relative risk of MI during the study period. When other gainfully employed were used as reference group, the relative risk excess was more pronounced (table 2). The incidence of MI among female drivers showed no tendency to be increased compared to other female manual workers during 1977-96 (not shown in the table): $\mathrm{RR}=0.80$ ( $95 \%$ CI 0.44 to 1.45 ). However, the confidence interval was wide due to small numbers ( 14 cases among female drivers).

The average annual incidence of MI among drivers paralleled the trend in the general male population throughout the whole study period, although at a higher level (table 3 and fig 1). During 1977-96 the average yearly change in incidence was -1.7 per 10000 person-years for bus drivers, -0.9 for taxi drivers, and -1.1 for lorry drivers (table 3 ). Thus, in absolute terms, the decrease in incidence was most pronounced for bus drivers. In relative terms the pattern was similar, with the highest average yearly change in incidence for bus drivers $(-3.2 \%)$. Analyses of the change in incidence starting from 1981 (the general peak in MI incidence) instead of 1977 resulted in a more marked average yearly change in incidence in particular for taxi drivers: $-2.1 \%$ starting from 1977, and $-4.1 \%$ starting from 1981 (not shown in the table). There were not enough female cases to calculate the average annual incidence of MI among female drivers.

In order to study the relative risk among drivers with longer job duration we restricted the analyses to persons holding the same type of job in two censuses. The results were similar to those reported in table 2, although the 
Table 1 Number of male cases and controls with information on occupation

\begin{tabular}{|c|c|c|c|c|c|c|}
\hline & \multicolumn{2}{|c|}{$1977-84$} & \multicolumn{2}{|c|}{$1985-96$} & \multicolumn{2}{|c|}{$1977-96$} \\
\hline & Cases & Controls & Cases & Controls & Cases & Controls \\
\hline All drivers & 571 & 1361 & 612 & 4711 & 1183 & 6072 \\
\hline Bus drivers* & 110 & 246 & 131 & 1093 & 241 & 1339 \\
\hline Taxi drivers* & 139 & 287 & 176 & 1149 & 315 & 1436 \\
\hline Lorry drivers* & 341 & 853 & 320 & 2628 & 661 & 3481 \\
\hline Other gainfully employed & 8919 & 29685 & 10262 & 100585 & 19181 & 130270 \\
\hline Other manual workers $\dagger$ & 3315 & 9954 & 3628 & 29639 & 6943 & 39593 \\
\hline $\begin{array}{l}\text { Total (all drivers and other gainfully } \\
\text { employed) }\end{array}$ & 9490 & 31046 & 10874 & 105296 & 20364 & 136342 \\
\hline
\end{tabular}

downward trend was more pronounced for taxi drivers. For bus drivers the relative risks were 1.45 (95\% CI 1.05 to 1.99 ) $1977-84$ and 1.08 (95\% CI 0.87 to 1.34 ) 1985-96. For taxi drivers the corresponding relative risks were 1.54 (95\% CI 1.15 to 2.04 ) $1977-84$ and 1.19 (0.96 to 1.47 ) 1985-96; and for lorry drivers 1.16 (0.92 to 1.46 ) $1977-84$ and 1.22 ( 1.05 to $1.43)$ 1985-96.

Since the percentage of drivers with foreign ethnic background increased during the study period ( $8 \%$ of drivers included 1977-84 were foreign born and 18\% 1985-96) we also analysed the relative risks of MI among drivers standardised for birth country. However, this did not have much influence on the risk estimates.

\section{DISCUSSION}

The initially clearly increased incidence of MI for professional drivers gradually approached the incidence for other manual workers. Even so, taxi and lorry drivers continued to have an increased incidence of MI in the latter part of the study period (1985-96). Bus drivers had the most favourable trend in MI incidence during the study period. Analysis of relative risk for bus drivers over the period 1985-96 indicated no excess risk (table 2). However, this point estimate is sensitive to the choice of cut-offs for the time periods. The analysis of incidence per two year period (fig 1) indicated that the incidence of MI still tended to be higher among bus drivers than among other manual workers, and close to the incidence among lorry drivers.

The underlying causes for the decrease in incidence of MI among professional drivers are unclear, although it is likely that the decline in risk to some extent may be attributed to changes in major known risk factors. When coronary risk factors in various occupational groups were studied in Oslo, Norway in the beginning of the 1970s, male taxi and bus drivers had a high smoking prevalence $165 \%$ and $55 \%$ respectively). ${ }^{22}$ A previous study of drivers in Stockholm 1992-93 showed that current smoking was more common among taxi $(47 \%)$ and lorry drivers (49\%), than among bus drivers (32\%) and in the general population (30\%). ${ }^{6} \mathrm{~A}$ possible explanation for the pronounced decrease in incidence of MI among bus drivers compared to other manual workers could be that smoking has declined relatively more among bus drivers than among other manual workers. The decreasing trend in MI incidence among drivers can hardly be explained by changes in ethnic background since the risk estimates were not much affected when we standardised for birth country.

Changes in the work environment may also be of importance for the reduced MI incidence. Information obtained from a national survey investigation performed in 1991 showed that a combination of high psychological demands and low control at work was common among bus drivers as well as among taxi drivers. Lorry drivers were, however, closer to the mean for other occupational groups in this respect. ${ }^{17}$ This type of psychosocial work conditions may be associated with an increased risk of $\mathrm{MI}^{5}$ and might in part explain the excess risk noted among professional drivers. In Stockholm an intervention study was carried out to investigate possible effects of improving working conditions for bus drivers. ${ }^{23}$ The intervention was designed to decrease traffic congestion, lessen passenger demands, and ease bus operation in general. The study showed fewer on-the-job hassles while driving, decreased systolic blood pressure and heart rate at work, and less perceived distress after work among drivers in the intervention group. A survey based on interviews among bus drivers in Stockholm identified several problems in the psychosocial daily work environment for this group, such as time pressure, selling and checking tickets, passenger contact, inappropriate work organisation, and threats and accidents. ${ }^{24}$ Possible changes in these work conditions in recent years may not yet have resulted in changes in the MI incidence. Motor exhaust exposure in the work environment is another possible risk factor for MI among drivers, although in a previous study motor exhaust exposure was not consistently associated with risk of myocardial infarction. ${ }^{25}$

Table 2 Relative risk of myocardial infarction (drivers compared to other manual workers or other gainfully employed subjects, RR adjusted for age group and calendar year)

\begin{tabular}{|c|c|c|c|c|}
\hline & \multicolumn{3}{|c|}{ RR $(95 \% \mathrm{Cl})$, compared to other manual workers } & \multirow{2}{*}{$\begin{array}{l}\text { RR }(95 \% \text { Cl), compared to other } \\
\text { gainfully employed subjects } \\
1977-96\end{array}$} \\
\hline & 1977-84 & $1985-96$ & 1977-96 & \\
\hline All drivers & $1.20(1.08$ to 1.33$)$ & $1.17(1.07$ to 1.28$)$ & $1.19(1.10$ to 1.27$)$ & $1.40(1.31$ to 1.50$)$ \\
\hline Bus drivers & $1.30(1.03$ to 1.64$)$ & $1.03(0.86$ to 1.25$)$ & $1.13(0.98$ to 1.31$)$ & $1.34(1.16$ to 1.55$)$ \\
\hline Taxi drivers & $1.38(1.12$ to 1.71$)$ & $1.35(1.14$ to 1.59$)$ & $1.36(1.19$ to 1.55$)$ & $1.62(1.43$ to 1.84$)$ \\
\hline Lorry drivers & $1.14(1.00$ to 1.30$)$ & $1.14(1.01$ to 1.29$)$ & 1.14 (1.04 to 1.25$)$ & 1.35 (1.23 to 1.47$)$ \\
\hline
\end{tabular}


Table 3 Incidence rates of myocardial infarction (standardised for the age distribution) per 10000 person-years, and average absolute and relative annual change in incidence with $95 \%$ confidence intervals

\begin{tabular}{|c|c|c|c|c|c|}
\hline & \multicolumn{3}{|l|}{ Incidence rates } & \multicolumn{2}{|c|}{ Average annual change in incidence $1977-96$} \\
\hline & 1977-84 & $1985-96$ & $1977-96$ & $\Delta$ incidence & $\%$ change in incidence \\
\hline $\begin{array}{l}\text { All drivers } \\
\text { Bus drivers } \\
\text { Taxi drivers } \\
\text { Lorry drivers } \\
\text { Other gainfully employed } \\
\text { Other manual workers } \\
\text { Total (all drivers and other gainfully } \\
\text { employed) }\end{array}$ & $\begin{array}{l}62.5(56.7 \text { to } 68.3) \\
73.2(54.0 \text { to } 92.3) \\
75.3(59.1 \text { to } 91.5) \\
59.2(52.1 \text { to } 66.4) \\
45.5(44.6 \text { to } 46.5) \\
50.7(48.8 \text { to } 52.6) \\
46.3(45.4 \text { to } 47.3)\end{array}$ & $\begin{array}{l}50.4(46.0 \text { to } 54.8) \\
45.1(36.7 \text { to } 53.6) \\
61.3(50.7 \text { to } 71.8) \\
48.9 \text { (42.8 to } 55.1) \\
35.2(34.5 \text { to } 35.9) \\
41.9(40.5 \text { to } 43.3) \\
35.8(35.1 \text { to } 36.4)\end{array}$ & $\begin{array}{l}55.3(51.7 \text { to } 58.8) \\
56.3(47.2 \text { to } 65.5) \\
66.9(57.8 \text { to } 75.9) \\
53.1(48.4 \text { to } 57.7) \\
39.3(38.7 \text { to } 39.9) \\
45.4(44.3 \text { to } 46.5) \\
40.0(39.4 \text { to } 40.6)\end{array}$ & $\begin{array}{l}-1.1(-1.6 \text { to } 0.6) \\
-1.7(-2.8 \text { to }-0.7) \\
-0.9(-2.4 \text { to } 0.6) \\
-1.1(-1.5 \text { to }-0.6) \\
-0.9(-1.1 \text { to }-0.8) \\
-0.7(-1.0 \text { to }-0.4) \\
-1.0(-1.1 \text { to }-0.8)\end{array}$ & $\begin{array}{l}-2.3(-3.3 \text { to }-1.3) \\
-3.2(-5.4 \text { to }-1.0) \\
-2.1(-4.0 \text { to }-0.2) \\
-2.2(-3.5 \text { to }-0.9) \\
-2.4(-2.6 \text { to }-2.1) \\
-1.6(-2.0 \text { to }-1.2) \\
-2.4(-2.6 \text { to }-2.2)\end{array}$ \\
\hline
\end{tabular}

The trend in MI incidence persisted when the study was restricted to persons holding the same type of job in two censuses. This type of restriction most likely leads to a reduced misclassification of exposure as well as a reduced proportion of persons with short job duration. However, for taxi drivers the downward trend was more favourable with this restriction, indicating an effect of selection towards more healthy workers among occupationally stable subjects. In the present study it was uncommon to move between driver categories, and only about 3\% of the drivers reported working in two different driver categories in the two censuses preceding inclusion.

In the general population of Sweden the decrease in MI incidence during the 1980s and 1990s has been attributed in part to changes in major risk factors amongst the population. ${ }^{8}{ }^{26-28}$ In Stockholm County about $50 \%$ of the working population were daily smokers in the beginning of the 1970s compared to $24 \%$ in $1994 .{ }^{29}$ However, the percentage of men who are overweight has increased..$^{29}$

To explain time trends is a very important issue. This study takes advantage of unique possibilities in Sweden to use information from MI and population registers that enables studies of long term time trends in first MI in specific occupational groups. We are not aware of any previous studies of long term time trends in the incidence of first MI among professional drivers. Our findings concerning time trends in MI incidence among the general population are consistent with those from previous studies using a similar methodology. ${ }^{10-12}$ The relative risks from the present study are basically consistent with those from the study of MI among bus, taxi, and lorry drivers in Stockholm 1992-93, ${ }^{6}$ although

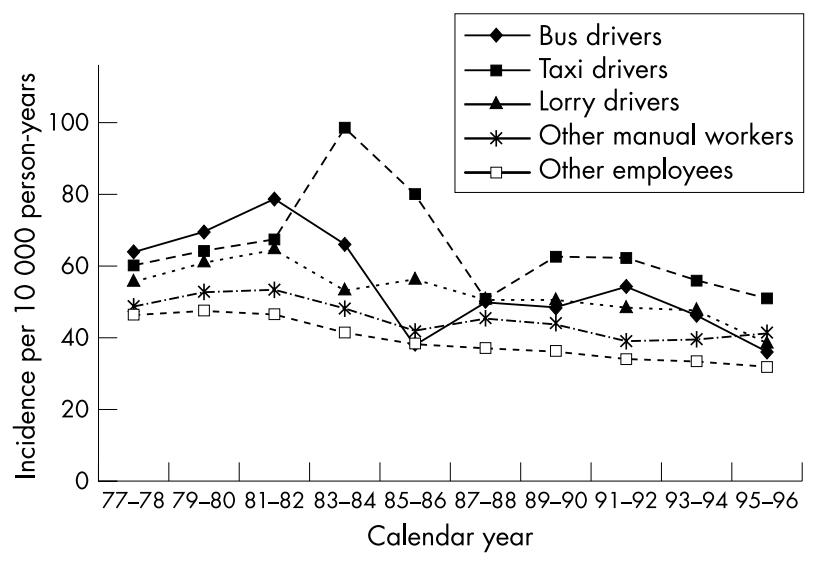

Figure 1 Time trends in the incidence of acute myocardial infarction among male professional drivers in Stockholm 1977-96 (standardised for the age distribution). bus drivers had the most pronounced excess risk of MI in that study.

An obvious strength of the present study is the possibility to compare incidence rates in both absolute and relative terms. Of importance also is the large study base, including the entire population of Stockholm County during 20 years. In this study base we were able to identify all first MI cases. Even though we have such a large study base, the numbers of cases in some occupational groups are small and the estimates of annual incidence are often accompanied by wide confidence intervals. For example, the pronounced peak in incidence for taxi drivers in 1983-84 could be due to random variation (fig 1). We did not have information on traditional risk factors for MI but since it is a descriptive study, with the main objective to investigate time trends in the incidence of MI, this should not be regarded as a major limitation. We do have information on important demographic factors such as gender, age distribution, and socioeconomic conditions as well as how the occupation has changed over time.

We identified cases of acute MI in the study population through the combined use of hospital discharge registers and deaths records. The method for identifying non-fatal cases has been previously evaluated and found to give a very high agreement with diagnostic criteria of $\mathrm{MI}^{12}{ }^{14}{ }^{15}$ and the loss of deaths from the national registry of causes of death records is negligible. The classification of occupation was based on census information with self-reported data, and the occupational title may have been miscoded for some men. However, since misclassification of occupation would be present throughout the whole time period the trend in MI incidence is not likely to be substantially affected. Also, any misclassification of occupation would probably be unrelated to the diagnosis of MI, which means that the relative risk estimates may have been biased towards one. To get a reasonable restriction backwards in time, with respect to the experience of working as a driver and disease outcome, we restricted the definition of occupation to two censuses preceding the year of inclusion (two censuses preceding inclusion were available for the whole study period). Including only the most recent census led to a reduction of cases since many drivers retired at ages 60-65, although they had been driving for a long time. Analyses using this criterion gave the same results except that the confidence intervals were wider. We had the possibility to exclude controls that had a MI before they were selected only for the period 198596. The 2825 controls that were excluded in this way amounted to about $2 \%$ of the controls in this period. Additional analyses for the period 1985-96 with all controls included showed that the relative risks were not affected (minor change in the second decimal). Therefore, the results for 1977-84 would probably remain about the same if 
Table A1 Classification of professional drivers by means of combining the occupational code for "motor vehicle driver" (code 633) with the branch of industry code

\begin{tabular}{|c|c|c|c|c|}
\hline \multicolumn{2}{|c|}{ Occupational code 633} & \multirow{2}{*}{$\begin{array}{c}\text { Bus drivers } \\
7112\end{array}$} & \multirow{2}{*}{$\begin{array}{c}\text { Taxi drivers } \\
7113\end{array}$} & \multirow{2}{*}{$\begin{array}{l}\text { Lorry drivers } \\
3111-3909,5010-5029,6100-6320,7114,7201-7202, \\
8101-8103,9201-9209\end{array}$} \\
\hline 1970 census & Branch of industry code & & & \\
\hline 1975 census & Branch of industry code & 7112 & 7113 & $\begin{array}{l}3111-3909,5010-5029,6100-6320,7114,7201-7202, \\
8101-8103,9201-9209\end{array}$ \\
\hline 1980 census & Branch of industry code & 7112 & 7113 & $\begin{array}{l}3111-3909,5011-5029,6100-6320,7114,7201-7202, \\
8101-8103,9201-9209\end{array}$ \\
\hline 1985 census & Branch of industry code & 71120 & 71130 & $\begin{array}{l}31111-39090,50110-50209,61111-63202,71140, \\
72001-72002,81010-81030,92001-92009\end{array}$ \\
\hline 1990 census & Branch of industry code & 71120 & 71130 & $\begin{array}{l}31111-39090,50110-50209,61111-63202,71140, \\
72001-72002,81010-81030,92001-92009\end{array}$ \\
\hline
\end{tabular}

exclusion of controls with previous MI had also been possible for this period.

In conclusion, there was a decline in MI incidence, both among drivers and in the general population in Stockholm County during the study period. The MI incidence was increased in all three driver groups during 1977-84 compared to other manual workers. Among taxi and lorry drivers the increased relative risk of MI remained for 1985-96. The risk excess was most evident among taxi drivers. Our findings suggest the importance of preventive measures to reduce the risk of MI, in particular among taxi and lorry drivers.

\section{ACKNOWLEDGEMENTS}

We thank Robert Jakobsson for help with the coding of professional drivers.

\section{Authors' affiliations}

C Bigert, P Gustavsson, Department of Occupational and Environmental Health, Stockholm Center of Public Health, Stockholm, Sweden K Klerdal, N Hammar, Department of Epidemiology, Stockholm Center of Public Health, Stockholm, Sweden

J Hallqvist, Division of Social Medicine, Department of Public Health Sciences, Karolinska Institutet, Stockholm, Sweden

Funding: The study was financially supported by the Swedish Council for Working Life and Social Research (grant number 2001-1133) and the Stockholm Center of Public Health, Stockholm County Council.

Ethics approval: The study was evaluated and approved by the ethics committee of the Karolinska Institutet, Stockholm, Sweden.

\section{APPENDIX}

Table Al presents a classification of professional drivers.

\section{REFERENCES}

1 Morris JN, Heady JA, Raffle PAB, et al. Coronary heart-disease and physical activity at work. Lancet 1953;265:1053-7.

2 Belkic K, Emdad R, Theorell T. Occupational profile and cardiac risk: possible mechanisms and implications for professional drivers. Int I Occup Med Environ Health 1998;11:37-57.

3 Tüchsen F, Endahl LA. Increasing inequality in ischaemic heart disease morbidity among employed men in Denmark 1981-1993: the need for a new preventive policy. Int J Epidemiol 1999;28:640-4.

4 Evans GW. Working on the hot seat: urban bus operators. Accid Anal Prev 1994;26:181-93.

5 Belkic K, Landsbergis P, Schnall P, et al. Psychosocial factors: review of the empirical data among men. In: Schnall PL, Belkic K, Landsbergis P, Baker D, eds. The workplace and cardiovascular disease. Philadelphia: Hanley \& Belfus, Inc, 2000;15:24-46.

6 Bigert C, Gustavsson P, Hallquist J, et al. Myocardial infarction among professional drivers. Epidemiology 2003;14:333-9.

7 Wilhelmsen L, Johansson S, Ulvenstam G, et al. CHD in Sweden: mortality, incidence and risk factors over 20 years in Gothenburg. Int J Epidemiol 1989; 18:101-8.
8 Tunstall-Pedoe H, Kuulasmaa K, Mahonen M, et al. Contribution of trends in survival and coronary-event rates to changes in coronary heart disease mortality: 10-year results from 37 WHO MONICA project populations. Monitoring trends and determinants in cardiovascular disease. Lancet 1999;353:1547-57.

9 Rosen M, Alfredsson L, Hammar N, et al. Attack rate, mortality and case fatality for acute myocardial infarction in Sweden during 1987-95. Results from the national AMI register in Sweden. J Intern Med 2000;248:159-64.

10 Alfredsson L, Ahlbom A. Increasing incidence and mortality from myocardial infarction in Stockholm County. BMJ 1983;286:1931-3.

11 Hammar N, Ahlbom A. Recent trends in mortality from and incidence of myocardial infarction in Stockholm. BMJ 1987;294:609-10.

12 Linnersjö A, Hammar N, Gustavsson A, et al. Recent time trends in acute myocardial infarction in Stockholm, Sweden. Int J Cardiol 2000;76:17-21.

13 Hallqvist J, Lundberg $M$, Diderichsen $F$, et al. Socioeconomic differences in risk of myocardial infarction 1971-1994 in Sweden: time trends, relative risks and population attributable risks. Int J Epidemiol 1998;27:410-15.

14 Ahlbom A. Acute myocardial infarction in Stockholm - a medical information system as an epidemiological tool. Int J Epidemiol 1978;7:271-6.

15 Hammar N, Nerbrand C, Ahlmark G, et al. Identification of cases of myocardial infarction: hospital discharge data and mortality data compared to myocardial infarction community registers. Int I Epidemiol 1991;20:114-20

16 Hammar N, Alfredsson L, Smedberg M, et al. Differences in the incidence of myocardial infarction among occupational groups. Scand I Work Environ Health 1992;18:178-85.

17 Gustavsson P, Alfredsson L, Brunnberg $\mathrm{H}$, et al. Myocardial infarction among male bus, taxi, and lorry drivers in middle Sweden. Occup Environ Med 1996:53:235-40.

18 Sveriges officiella statistik, folk- och bostadsräkningen 1980, del 9, yrke, bilaga 7.

19 Sveriges officiella statistik, folk- och bostadsräkningen 1980, del 9, yrke, bilaga 6.

20 Statistics Sweden. Swedish socioeconomic classification. Stockholm: Reports on statistical co-ordination, 1982, 4 (English summary).

21 Alfredsson L, Hammar N, Gillström P. Increasing differences in myocardial infarction incidence between socio-economic groups in Stockholm. Nutr Metab Cardiovasc Dis 1995:99-104.

22 Holme I, Helgeland A, Hiermann I, et al. Coronary risk factors in various occupational groups: the Oslo study. Br J Prev Soc Med 1977;31:96-100.

23 Rydstedt LW, Johansson G, Evans GW. The human side of the road: improving the working conditions of urban bus drivers. J Occup Health Psychol 1998:3:161-71.

24 Byström-Valencia K, Brunnberg H, Gustavsson P. Rapport från Yrkesmedicinska enheten, 2002:2, Tiden går, Om bussförares psykosociala arbetsmilï.

25 Gustavsson P, Plato N, Hallqvist J, for the Stockholm Heart Epidemiology Program (SHEEP) study group, et al. A population-based case-referent study of myocardial infarction and occupational exposure to motor exhaust, other combustion products, organic solvents, lead, and dynamite. Epidemiology $2001 ; 12: 222-8$

26 Tornvall P, Båvenholm P, Hellénius ML, et al. A decrease in cardiovascular risk factors in healthy 40-year-old Swedish men between 1980-1983 and 19911992. J Cardiovasc Risk 1996;3:379-83.

27 Wilhelmsen L, Rosengren A, Lappas G. Relative importance of improved hospital treatment and primary prevention. Results from 20 years of the myocardial infarction register, Göteborg, Sweden. J Intern Med 1999;245: 185-91.

28 Rosengren A, Eriksson H, Larsson B, et al. Secular changes in cardiovascular risk factors over 30 years in Swedish men aged 50: the study of men born in 1913, 1923, 1933 and 1943. J Intern Med 2000:247:111-18.

29 Folkhälsorapport 1994. SoS-rapport 1994: 9, Socialstyrelsen, Stockholm, Sweden, 1994:51-6. 